\title{
O desenvolvimento do brincar em crianças com a Síndrome Congênita do Zika Vírus
}

\begin{abstract}
Resumo: Pela perspectiva educacional inclusiva, todas as crianças têm direito à educação, independentemente de sua condição socioeconômica, cultural ou deficiência. Tendo em conta tal perspectiva, o presente trabalho objetivou analisar a importância do brincar para o desenvolvimento das crianças com a Síndrome Congênita do Zika Vírus (SCZ) na visão das progenitoras. Destaca-se ainda os objetivos: perceber os aspectos do desenvolvimento da criança por meio das brincadeiras que realiza e identificar a opinião das progenitoras sobre o papel das brincadeiras na aprendizagem e suas percepções acerca da inclusão escolar dessas crianças. Para responder aos questionamentos foi realizado um estudo descritivo com a participação das progenitoras por meio de um questionário, além da observação de vídeos das crianças brincando. Assim, emergiram as seguintes categorias de análise: 1) o brincar da criança com SCZ; 2) o desenvolvimento da criança por meio da brincadeira e 3) a visão das progenitoras em relação a aprendizagem das crianças por intermédio das brincadeiras e a futura inclusão escolar. Dessa forma, destaca-se o quanto é importante fazer um trabalho lúdico dentro de contextos de desenvolvimento, podendo ser necessário adaptações na metodologia, nos recursos, materiais e atividades realizadas para a obtenção de uma resposta as necessidades de aprendizagem da criança com SCZ. Conclui-se que o brincar estreita vínculos e traz benefícios para o processo de desenvolvimento, contudo a percepção das progenitoras sobre a escola inclusiva revelou inseguranças e receios no que tange a inclusão das crianças pequenas nas escolas de Educação Infantil.
\end{abstract}

Palavras-chave: Educação Inclusiva. Síndrome Congênita do Zika Vírus. Brincar. Família. Educação Infantil.

\section{Introdução}

A inclusão educacional é de fundamental importância para a sociedade, pois é através dela que muitas crianças e jovens com necessidades educacionais especiais estão tendo acesso à educação escolar, haja vista que com a inclusão percebe-se que algumas barreiras encontradas pelas pessoas com deficiência estão diminuindo gradativamente.

Recentemente foi confirmado pelo Ministério da Saúde a relação entre a microcefalia e o Zika Vírus (BRASIL, 2015), vindo a ser chamada de Síndrome Congênita do Zika Vírus (SCZ) por alguns pesquisadores. A Portaria no 3.502/2017 do Ministério da Saúde institui estratégia de fortalecimento das ações do cuidado das
Márcia Pires Fernandes

Universidade Federal da Bahia - UFBA

marciaadilza@hotmail.com

Silvanne Ribeiro Santos Universidade Federal da Bahia - UFBA

silvanne.ribeiro@ufba.br

Fernanda Matrigani Mercado Gutierres de Queiroz

Universidade Federal da Bahia - UFBA

fernanda.queiroz@ufba.br 
crianças com diagnóstico ou suspeita de SCZ e outras síndromes congênitas. (BRASIL, 2017)

Não se sabe ainda o prognóstico do desenvolvimento das crianças que apresentam microcefalia decorrente desta Síndrome, devido ao fato de ser muito recente e não se manifestar da mesma maneira que outras formas de microcefalia. Portanto, a temática aqui proposta se mostra como carente de ampliação nas pesquisas, a fim de prover mais dados que corroborem para uma maior qualidade de vida dessas crianças.

Diante deste contexto atual que engloba as áreas da saúde e da educação, torna-se relevante uma reflexão sobre a prática do cuidar e do educar, permeados pela ludicidade, em contextos essenciais ao desenvolvimento humano como a família e a escola, favorecendo um ambiente que venha a possibilitar um bom desenvolvimento dos bebês e das crianças pequenas. Em relação as crianças com SCZ, é preciso conhecer suas características, como as deficiências e os comprometimentos que apresentam, sem esquecer de analisar as habilidades, as capacidades adquiridas e as possibilidades encontradas. Portanto, esse trabalho traz como objetivo geral analisar a importância do brincar para o desenvolvimento das crianças com SCZ, na visão das progenitoras. Além disso, apresenta-se os objetivos específicos, tais como: perceber os aspectos do desenvolvimento da criança por meio das brincadeiras que realiza e identificar a opinião das progenitoras sobre o papel das brincadeiras na aprendizagem e suas percepções acerca da inclusão escolar dessas crianças.

Estima-se que há no Brasil cerca de 2.653 casos confirmados de SCZ, surgidos entre os anos de 2015 a 2017. (AZEVEDO, 2017) Onde estão estes bebês e crianças? O país está dando a visibilidade e apoio que elas merecem e necessitam, seja em criação de políticas públicas, seja em formação adequada e ofertas de atendimento de profissionais de saúde e educação a esse público e seus familiares? Sendo assim, pelos dados oficiais, sabemos que teremos uma grande demanda dessas crianças em escolas da Educação Básica, por isso é necessário e urgente pensar na formação de profissionais e orientações as famílias, visando o acolhimento e estimulação a estas crianças por equipe multidisciplinar e estreitando laços entre família e escola. As estimulações dadas primeiramente pela família e, posteriormente, pela escola, podem contribuir significativamente para avanços consideráveis no desenvolvimento dessas crianças, bem como em melhor qualidade de vida. 
Justifica-se este estudo pela necessidade de debater um tema atual, ainda com escassas pesquisas, e, também pela possibilidade de auxiliar as famílias e professores da Educação Infantil a cerca da relevância de se trabalhar com brincadeiras em diferentes momentos e ambientes, oferecendo as crianças com a SCZ uma maneira prazerosa de aprendizagem, incentivando-as em seu desenvolvimento pleno.

\section{Educação Especial na perspectiva inclusiva}

A partir do século XX surge um novo paradigma e olhar em relação as pessoas com deficiências, resultantes em uma busca pelas suas potencialidades e saberes. Nesse processo, propõe-se uma escola inclusiva para que todos possam ser acompanhados em seu processo de aprendizagem.

Durante os últimos anos do século XX, discutiu-se com mais objetividade o direito à educação para todas as pessoas com ou sem deficiência, visando o respeito e a construção de práticas pedagógicas que atendessem as necessidades de todos os alunos com equidade. No Brasil, a Educação Inclusiva ganhou força em meados da década de 1990, decorrente das diversas lutas de movimentos sociais e das famílias de pessoas com deficiência na busca pelo ingresso de seus filhos nas escolas comuns e por melhores condições de vida.

Assim, ao longo do tempo foram surgindo documentos como: a Constituição Federal de 1988 (BRASIL, 1988), a Declaração Mundial sobre Educação para todos (UNESCO, 1990), a Declaração de Salamanca (UNESCO, 1994), a Lei de Diretrizes e Base da Educação Nacional no 9394/96 (BRASIL, 1996), a Convenção sobre os Direitos das Pessoas com Deficiência (ONU, 2007) e a Política Nacional de Educação Especial na Perspectiva da Educação Inclusiva (2008), entre outros.

A Constituição Federal de 1988 é clara, em seu artigo 206, Inciso I, com relação a "igualdade de condições de acesso e permanência na escola". (BRASIL, 1998) Além disso, a legislação brasileira determina que a educação da pessoa com deficiência seja realizada, preferencialmente na rede regular de ensino através da Lei de Diretrizes e Bases da Educação Nacional (LDB) nº . 9.394/96, em seu capítulo V, artigo 58.

A educação inclusiva possibilitou algumas mudanças na educação que vão desde algumas alterações curriculares, formações 
para os professores, adequações nas escolas como também em políticas educacionais mais igualitárias. Segundo esse contexto, Mendes (2006, p. 228) comenta que:

\begin{abstract}
Educar crianças com necessidades especiais juntamente com seus pares em escolas comuns é importante, não apenas para prover oportunidades de socialização e de mudar o pensamento estereotipado das pessoas sobre as limitações, mas também para ensinar o aluno a dominar habilidades e conhecimentos necessários para a vida futura dentro e fora da escola.
\end{abstract}

Os autores Stainback e Stainback (1999, p. 21) definem Educação Inclusiva como: "A prática da inclusão de todos, independentemente de seu talento, deficiência, origem socioeconômica ou cultural, em escolas e salas de aula provedoras, onde todas as necessidades dos alunos são satisfeitas". Essa prática trata da oferta de uma educação de qualidade e dos direitos de igualdade que as pessoas têm que ter durante o seu processo de aprendizagem nas escolas de ensino comum, tendo a mesma o dever de oferecer estratégias de ensino, espaço físico e recursos didáticos necessários para o Atendimento Educacional Especializado (AEE).

A Declaração de Salamanca (UNESCO, 1994) cita que, para uma escola ser inclusiva ela precisa ser um ambiente que ofereça as mesmas oportunidades de participar das atividades à todas as crianças, assegurando para as crianças com deficiência, o acolhimento e os recursos pedagógicos necessários para o seu desenvolvimento. Recentemente, conforme o artigo $2^{\circ}$ da Lei $n^{\circ}$ 13.146, de 6 de julho de 2015, a Lei Brasileira de Inclusão da Pessoa com Deficiência - Estatuto da pessoa com deficiência, define-se a pessoa com deficiência como:

[...] aquela que tem impedimento de longo prazo de natureza física, mental, intelectual ou sensorial, o qual, em interação com uma ou mais barreiras, pode obstruir sua participação plena e efetiva na sociedade em igualdade de condições com as demais pessoas. (BRASIL, 2015)

Cabe salientar que a perspectiva educacional inclusiva, não se refere somente as pessoas com deficiência, mas a uma educação de qualidade, a valorização da diversidade, das potencialidades e vários outros fatores em relação ao atendimento disponibilizado as pessoas com deficiências e principalmente na promoção do respeito mútuo nos processos de ensino e aprendizagem. 


\section{A criança com Síndrome Congênita do Zika Vírus: aspectos familiar, social e escolar}

A criança com a SCZ assim como qualquer outra tem direito a escolarização, conforme assegurado pela LDB no 9394/1996. (BRASIL, 1996) Apesar do comprometimento e dificuldades acometidas ao seu desenvolvimento, essa criança possui capacidades e habilidades que possibilitam a sua aprendizagem de acordo com seu tempo e especificidade. No entanto, precisam ser estimuladas desde os primeiros meses de vida e a escola deve estar preparada para essa acolhida e estimulação. Acerca da inclusão nas escolas Mittler (2003, p. 16) destaca:

A inclusão não diz respeito a colocar as crianças nas escolas regulares, mas a mudar as escolas para torná-las mais responsivas às necessidades de todas as crianças; diz respeito a ajudar todos os professores a aceitarem a responsabilidade quanto à aprendizagem de todas as crianças nas suas escolas e prepará-los para ensinarem aquelas crianças que estão atual e correntemente excluídas das escolas por qualquer razão.

De acordo com o documento do Ministério da Saúde: Diretrizes de estimulação precoce: crianças de zero a 3 anos com atraso no desenvolvimento neuropsicomotor decorrente de microcefalia, em decorrência da SCZ, estas crianças podem apresentar alterações significativas nas áreas motora e cognitiva dependendo do grau de comprometimento do Sistema Nervoso Central. (BRASIL, 2016a) O Protocolo de atenção à saúde (2017), em resposta à ocorrência de microcefalia relacionada à infecção pelo vírus Zika, menciona que o comprometimento cognitivo ocorre em cerca de $90 \%$ dos casos. Todavia, ainda há muito desconhecimento e falta de informações que incidem nas condições de uma melhor qualidade de vida a essas crianças, seja na família ou no ambiente escolar.

Em grande parte dos casos conhecidos, as crianças com a SCZ apresentam microcefalia, que segundo Torres e Tapia (2017) é a condição na qual o bebê nasce com o crânio do tamanho menor que o esperado para a mesma idade, sexo e raça, bem como podem apresentar alterações neurológicas, hipertonia, convulsões e espasticidade. O Ministério da Saúde (BRASIL, 2016b) adotou a medida do perímetro cefálico igual ou inferior a 31,9 cm para meninos e 31,5 cm para meninas nascidos após 
37 semanas de gestação, sob recomendação da Organização Mundial de Saúde (OMS).

Em relação a área motora, a SCZ pode trazer complicações que variam de acordo com o comprometimento cerebral da criança afetada, ou seja, no nível mais leve a criança vai ter dificuldades de motricidade fina, já na condição mais grave ela pode apresentar dificuldades em andar, equilibrar-se, de coordenação e até na hora de pegar ou carregar com as mãos alguns objetos.

$\mathrm{Na}$ área física, as dificuldades muitas vezes afetam sua mobilidade limitando-a, além de trazer complicações na coordenação geral. De acordo com Van Eyken e Sá (2017), as crianças com a SCZ podem apresentar artrogripose ${ }^{1}$ múltipla congênita, pés tortos congênitos, quadris luxados, hiperextensão dos joelhos, membros superiores em rotação interna, adução de ombros, extensão dos cotovelos e pronação dos antebraços.

Já na área cognitiva, a criança pode apresentar dificuldade na linguagem, em memorizar, em concentrar-se para fazer alguma atividade e até para resolver problemas, de acordo com a sua faixa etária, segundo Torres e Tapia (2017). A perda auditiva afeta o desenvolvimento da criança no que diz respeito a comunicação, mas isso vai depender do seu grau de comprometimento. $\mathrm{Na}$ área visual, podem ocorrer lesões maculares e perimaculares bilaterais, bem como anormalidades do nervo óptico, conforme exposto por Freitas e colaboradores (2016). Portanto, é importante que a criança seja examinada por especialistas, logo que nasce, para verificar se foi afetada e principalmente, o grau de comprometimento para o quanto antes começar o tratamento adequado.

Levando em consideração o nível de comprometimento intelectual das crianças com SCZ, compreende-se que haverá uma grande demanda originária dessas crianças, por isso é necessário pensar no acolhimento durante a sua estimulação multidisciplinar e no acesso delas ao contexto educacional, o qual pode contribuir para alguns avanços em seu desenvolvimento. Segundo Fonseca (1998, p. 68):

\footnotetext{
A aprendizagem depende, portanto, do desenvolvimento prévio e anterior, ao mesmo tempo que depende do desenvolvimento proximal do sujeito. Não estão só em causa as atividades que ele pode aprender com a ajuda e a intervenção intencional dos outros, ou seja, ele aprende por humanização, por meio de mediatização. As pessoas que rodeiam o sujeito, ou melhor, a
} 
criança (o mediatizado), não são objetos passivos ou simples instrumentos do seu desenvolvimento, mas sim companheiros ativos que guiam, planificam, regulam, selecionam, filtram, começam e terminam as condutas da criança. São agentes do seu desenvolvimento.

Pensando nesse enfoque faz-se necessário o cuidado precoce e com estas crianças, a educação precoce, que contribui para orientar adequadamente os programas educacionais. Coll, Palacios e Marchesi (1995, p. 247) entendem como educação precoce:

Toda educação deve começar precocemente, mesmo a da criança que evolui e progride normalmente. Por isso mesmo, deve-se começar precocemente -desde as primeiras semanas de vida e, indubitavelmente, antes do ingresso na escola -a educação da criança com problemas de desenvolvimento, quaisquer que sejam estes problemas $[\ldots]$.

Para as crianças que apresentam a SCZ, é de suma importância que aconteça a estimulação precoce durante o seu desenvolvimento, já que nesse período não só as crianças com microcefalia, mas todas as crianças, nos seus primeiros anos de vida, considerados como uma fase de aquisição e transformações cognitivas, motoras e afetivas necessitam de cuidados e a família apresenta um importante papel que é levar a criança para participar de algum programa de estimulação precoce assim que sua saúde clínica esteja estabilizada. Nesse sentido, o Ministério da Saúde afirma que o Programa de Estimulação Precoce objetiva "[...] estimular a criança e ampliar suas competências, abordando os estímulos que interferem na sua maturação, para favorecer o desenvolvimento motor e cognitivo". (BRASIL, 2016 c, p. 29)

A estimulação adequada traz benefícios para todas as crianças, independentemente de ela manifestar alguma deficiência ou não. Assim, para a criança com microcefalia decorrente da SCZ seus avanços são ainda mais benéficos, já que elas apresentam alguns prejuízos no seu desenvolvimento neuropsicomotor. O programa de estimulação precoce traz como objetivos gerais:

1. Maximizar o potencial de cada criança inserida no programa por meio da estimulação em âmbito ambulatorial e também em seu ambiente natural, estabelecendo o tipo, o ritmo e a velocidade dos estímulos e designando, na medida do possível, um perfil de reação. 
2. Potencializar a contribuição dos pais ou responsáveis, de modo que eles interajam com a criança de forma a estabelecer mutualidade precoce na comunicação e afeto, prevenindo o advento de distúrbios emocionais e doenças cinestésicas.

3. Promover um ambiente favorável para o desempenho de atividades que são necessárias para o desenvolvimento da criança.

4. Oferecer orientações aos pais e à comunidade quanto às possibilidades de acompanhamento desde o período neonatal até a fase escolar da criança.

5. Promover modelo de atuação multiprofissional e interdisciplinar.

6. Disseminar informações incentivando e auxiliando a criação de programas de estimulação precoce. (BRASIL, 2006, p.30-31)

Em relação ao seu desenvolvimento, pode ser que as com microcefalia precisem de mais tempo para apropriar-se da fala, como também podem manifestar atraso no seu processo de deambulação, bem como, para aprender as habilidades necessárias para cuidar de si, com autonomia.

Partindo desses pressupostos, deve-se considerar a grande probabilidade de que as crianças enfrentem dificuldades, por isso existe a necessidade dos estímulos precoces, anteriores ao período escolar, os quais a escola deverá dar continuidade. É provável que seja necessário mais tempo para sua aprendizagem, isso significa que em seu cotidiano, a criança com microcefalia poderá apresentar algumas dificuldades para aprender, compreender e fazer atividades que são realizadas facilmente por outras pessoas, pois elas apresentam uma alteração no seu desempenho funcional. Assim, de acordo com a Classificação Internacional de Funcionalidade, Incapacidade e Saúde (CIF) funcionalidade é: "um termo que engloba todas as funções do corpo, atividades e participação". (ORGANIZAÇÃO MUNDIAL DA SAÚDE, 2004, p. 7)

Em relação a estimulação precoce da criança com SCZ, Lamônica e Ribeiro (2018) expõe sobre a urgência deste debate, principalmente nas áreas da educação e da saúde e o impacto destas ações no desenvolvimento das crianças.

Dessa forma, torna-se importante a inclusão dessas crianças logo cedo no ambiente escolar, ou seja, na creche, para que aconteça uma interação social entre elas e outras crianças visando o seu desenvolvimento integral. Para que isso se torne possível é essencial que a família da criança faça sua matrícula em uma 
escola de Educação Infantil. Cabe destacar, que em alguns casos, há atraso nesta matrícula por orientação médica, como por exemplo, referente as crianças com microcefalia que estão apresentando convulsões não responsivas aos medicamentos, todavia, assim que houver a liberação médica, deverão matriculá-la.

A parceria escola e família são imprescindíveis para que ocorra uma educação de qualidade. É indispensável que as famílias acompanhem a vida escolar das crianças, que percebam a importância de relacionar-se com a escola na procura de um objetivo em comum, como é a educação de qualidade para as crianças. Por outro lado, a escola é responsável por promover meios de aproximação com as famílias e a comunidade, orientando e mostrando que princípios de cuidar e educar não são papéis exclusivos da escola e sim, de todos. Por isso, a escola de Educação Infantil sempre deve envolver as famílias das crianças em seu desenvolvimento, não para falar dos problemas, mas para apoiálas e orientá-las, incentivando-lhes a promover brincadeiras e interações diversas com os bebês e as crianças pequenas.

\section{A criança com a SCZ na escola de Educação Infantil e a importância do brincar para o desenvolvimento infantil}

Na etapa da Educação Infantil, a criança passa a se desenvolver em um espaço formal e coletivo, através de diversas descobertas que devem ser possibilitadas por uma variedade de experiências. Tais experiências devem favorecer e contribuir para seu desenvolvimento pleno. No caso específico do bebê e/ou criança com SCZ, a creche/ escola de Educação Infantil deve auxiliá-los na aquisição de habilidades necessárias, contando com estimulações diversas, complementando a ação da família, pois, de acordo com Coll, Palacios e Marchesi (1995, p. 248):

A educação precoce inclui um conjunto de procedimento que não são exclusivos dessa idade, mas que adquirem nela uma importância singular. Os programas educativos de estimulação antecedente, nos quais diferentes padrões de estímulos são apresentados e manejados com a função de assinalar o meio, de proporcionar discriminações, de enriquecer e ordenar a experiências das crianças e até mesmo, de induzir movimentos e comportamentos simples. 
Além da estimulação precoce com profissionais especializados da área da saúde como médicos, fisioterapeutas, terapeutas ocupacionais, fonoaudiólogos e psicólogos, entre outros, é recomendado para o seu desenvolvimento físico, social e cognitivo, que as crianças com a SCZ frequentem a creche ou a pré-escola o quanto antes seja autorizado pela equipe especializada. Compreendendo o desenvolvimento humano numa perspectiva histórico-cultural é durante a primeira infância que as crianças adquirem experiências essenciais, as quais impactarão sobremaneira nos períodos posteriores da sua vida. Assim, os vínculos que estabelecem com os outros e em contextos nos quais diferentes interações são proporcionadas são fundantes desse desenvolvimento.

Considerando a escola de Educação Infantil como um potencial loquos de desenvolvimento humano, ampliaremos a seguir em que consiste tal espaço e sua importância para o desenvolvimento integral dos bebês e crianças pequenas. Assim, as Diretrizes Curriculares Nacionais para a Educação Infantil - DCNEI (BRASIL, 2010,p. 12), definem Educação Infantil como:

Primeira etapa da educação básica, oferecida em creches e préescolas, às quais se caracterizam como espaços institucionais não domésticos que constituem estabelecimentos educacionais públicos ou privados que educam e cuidam de crianças de 0 a 5 anos de idade no período diurno, em jornadas integral ou parcial, regulados e supervisionados por órgão competente do sistema de ensino e submetidos a controle social.

É uma luta diária no nosso país que todas as crianças tenham direito a uma Educação Infantil gratuita, inclusiva e de boa qualidade, assegurando-lhes o que consta na legislação. Ademais,nesse espaço formal e coletivo de aprendizagens, devem ser garantidos às crianças direitos fundamentais, tais como expõe a Base Nacional Comum Curricular (BRASIL, 2017), como os direitos de conviver, brincar, participar, explorar, expressar e conhecer-se. Sendo assim, a concepção de criança de acordo com as DCNEI é:

Sujeito histórico e de direitos que, nas interações, relações e práticas cotidianas que vivencia, constrói sua identidade pessoal e coletiva, brinca, imagina, fantasia, deseja, aprende, observa, experimenta, narra, questiona e constrói sentidos sobre a natureza e a sociedade, produzindo cultura. (BRASIL, 2010, p.12) 
Através de estudos e observações acerca do desenvolvimento dos bebês e de crianças com SCZ, sabe-se que possuem algumas limitações a serem enfrentadas no seu dia a dia escolar, portanto é preciso usar de estratégias existentes nesse contexto educativo para que eles se sintam incluídos durante sua permanência na creche ou pré-escola.

Nesse sentido, os pedagogos que atuam nesse nível da Educação Básica devem ter uma formação ampla, com conhecimentos diversificados, porém com instrumentos específicos e recursos adequados para atender todas às dificuldades e limitações impostas pela nova situação que se apresenta. Devem, ademais, ser capazes de desempenhar um trabalho como mediador e provedor da educação inclusiva, na ascensão da aprendizagem em distinto período de crescimento do indivíduo nos vários níveis do seu processo educacional.

Neste contexto, o brincar deve ser usado no planejamento como um instrumento essencial durante a mediação dos conhecimentos para as crianças nos processos de ensino e aprendizagem. Segundo Kishimoto (2010, p. 1) podemos definir o brincar como uma atividade "[...] livre, que surge a qualquer hora, iniciada e conduzida pela criança; dá prazer, não exige como condição um produto final; envolve, ensina regras, linguagens, desenvolve habilidades e introduz a criança no mundo imaginário".

Assim, o princípio de cuidar e educar as crianças com deficiência, é um aprendizado para todos os profissionais, principalmente para os envolvidos no processo educativo. Além de ser um grande desafio, pois de acordo com a perspectiva educacional inclusiva, todo individuo é único e capaz de aprender desde que se utilizem de metodologias e recursos adequados para cada necessidade. (BRASIL, 2008)

Especificamente sobre o uso do brinquedo na escola, Friedmann (1992) afirma que esse é o parceiro da criança na brincadeira e ao manipulá-lo de maneiras diferentes, a criança passa a conduzir à ação e à representação, a agir e a imaginar. O brinquedo atua de várias formas no decorrer do processo educativo, uma delas é no desenvolvimento da motricidade fina e grossa, bem como, nas habilidades do pensamento da criança que envolve a imaginação, a criatividade, as tomadas de decisões e as suas interpretações. O brinquedo também é muito indicado pelos profissionais da saúde, na estimulação precoce das crianças com deficiência. 
O brincar como linguagem primordial na infância possui, também, uma função fundamental, na vida da criança com SCZ, tanto nas atividades realizadas individualmente quanto com a mediação de um adulto. Para as crianças com deficiência, existe um cuidado maior já que elas precisam de atividades estimuladoras adequadas que venham a contribuir no seu processo de desenvolvimento, devido aos seus comprometimentos. Como afirma Friedmann (1992), todas as crianças devem ser estimuladas e necessitam brincar para se desenvolverem, porém, as crianças com deficiência, necessitam dessa estimulação como fator essencial para o seu desenvolvimento. Sendo assim, Siaulys (2005, p. 10) salienta que:

Brincando, a criança desenvolve os sentidos, adquire habilidades para usar as mãos e o corpo, reconhece objetos e suas características, textura, forma, tamanho, cor e som. Brincando, a criança entra em contato com o outro, desenvolve o físico, a afetividade, torna-se ativa e curiosa.

Lembrando que essas crianças podem brincar com os mesmos brinquedos que as outras, o diferencial está na sua escolha, pois é importante que essa seleção seja realizada de acordo com o nível de desenvolvimento, visando estimulá-lo. Dessa forma, é necessário conhecer a funcionalidade apresentada por esta criança, conhecer e analisar seus comprometimentos motores e cognitivos dentre outros, com o intuito de verificar se há necessidade de alguma adaptação no brinquedo e na brincadeira, visando que a sua oferta seja a mais adequada às características da criança. Aconselha-se que ao escolher o brinquedo é pertinente comprar aqueles com cores fortes, coloridos e que emitam som, para poder estimular diversas habilidades de maneira concomitante.

O brinquedo também pode servir como um instrumento de interação das crianças com a família e o meio social em que elas vivem, pois por meio da sua utilização as crianças podem demonstrar momentos interessantes de trocas relacionais e estreitamento de vínculos afetivos. Nessa perspectiva, o brincar é um momento importantíssimo na vida da criança, por ter uma grande relevância no desenvolvimento infantil. É durante o processo de desenvolvimento que podemos perceber os vários avanços nas áreas afetiva, cognitiva e social da criança, além de ser o momento para que aconteça também o processo de interação social da criança no ambiente escolar e no familiar. Assim, por 
intermédio do brincar é possível também observar alguns aspectos do desenvolvimento da criança como na área motora, a lateralidade, o domínio espacial, concentração e muitos outros estímulos relacionados a aprendizagem e a construção do conhecimento. (PEREIRA; LIMBERGER, 2014)

Nesse sentido, Haetinger (2005) afirma ser necessário desenvolver atividades em um clima acolhedor que possa favorecer a aceitação, pois, só assim as interações serão verdadeiras e todos os envolvidos poderão crescer e aprender em conjunto. Assim, é de fundamental importância que os contextos de desenvolvimento das crianças com SCZ, como família e escola,sejam permeados de experiências diversas e ricas com o brincar e brinquedos adequados.

\section{Método}

Os dados aqui apresentados foram coletados por meio de pesquisa qualitativa descritiva, realizada em uma cidade do Nordeste brasileiro, no período de outubro de 2017 a janeiro de 2018. Foram utilizados os seguintes instrumentos: questionários com perguntas abertas e fechadas, vídeos das crianças no momento do brincar, gravados por um familiar e encaminhados às pesquisadoras, e um protocolo de análise dos componentes de uma atividade, elaborado por Ferland (2009) e adaptado para este estudo, visando auxiliar na análise dos vídeos.

Os questionários objetivaram analisar a opinião das famílias sobre o desenvolvimento das crianças com SCZ por meio do brincar e o que pensam da aprendizagem utilizando as brincadeiras. O protocolo de análise dos componentes de uma atividade, possibilitou a coleta dos dados sobre os componentes ligados aos sentidos: como a visão, audição, tato e sentido do movimento vestibular, a motricidade global e fina, a cognição e a linguagem compreensiva e expressiva, observados nas brincadeiras exibidas nos vídeos.

Participaram deste estudo: duas crianças pequenas diagnosticadas com a SCZ, ambas do sexo masculino com 1 ano e 10meses e 1 ano e 11 meses de idade, respectivamente. Eles recebem acompanhamento de profissionais da área da saúde, ainda não frequentavam a creche e apresentaram algumas características como atraso no desenvolvimento motor e da linguagem. Também foram participantes, suas respectivas progenitoras, sendo uma mãe com 27 e a outra com 32 anos, ambas oriundas de camadas populares. 
Uma das mães participante possui o ensino médio completo e a outra não informou sua escolaridade. Ambas não trabalham fora de casa e uma delas tem mais um filho. Outra característica em comum nessas famílias é que o pai trabalha fora de casa, tornandose o principal responsável pelo sustento financeiro da família e as mães se responsabilizam pelos cuidados da casa, dos filhos e acompanhamentos relativos à saúde.

Para analisar os dados, foi necessário desenvolver estudos bibliográficos sobre a temática, com base na fundamentação teórica e pesquisa na rede de computadores. Foram analisados os dados coletados por meio do questionário e análise dos vídeos, com o auxílio do protocolo supracitado dos quais, emergiram as áreas temáticas expostas nos resultados. Em continuidade, para a construção da análise, foi necessário assistir aos vídeos, e neste procedimento as pesquisadoras foram tecendo uma relação com as atividades propostas no protocolo. Essa relação deu-se através da captura dos gestos, expressões e movimentos corporais das crianças percebidos nas imagens e pelos sons produzidos pelas mesmas, seus responsáveis e/ou brinquedos utilizados durante a gravação do vídeo.

Ao enlaçar esses dados com os obtidos por meio dos questionários, evidenciou-se as categorias de análise desta pesquisa, por meio da análise de conteúdo, conforme proposto por Bardin (2011)que foram: o brincar da criança com a SCZ, seu desenvolvimento por meio das brincadeiras e a visão das progenitoras em relação a aprendizagem das crianças por intermédio das brincadeiras e a futura inclusão escolar. A seguir detalhar-se-á os resultados e será apresentada a discussão.

\section{Resultados e Discussão}

Retomando o objetivo desta pesquisa, que é analisar a importância do brincar para o desenvolvimento das crianças com SCZ, na visão das progenitoras, apresentaremos agora os resultados de acordo com as categorias criadas: 1) o brincar da criança com a SCZ; 2) o desenvolvimento da criança por meio das brincadeiras e 3)a visão das progenitoras em relação a aprendizagem das crianças por intermédio das brincadeiras e a futura inclusão escolar: 


\section{A) O brincar da criança com Síndrome Congênita do Zika Vírus}

De acordo com o resultado da pesquisa pôde-se perceber que a importância dada ao brincar pelas progenitoras foi bastante semelhante. Para ambas as mães, as atividades com brincadeiras ajudam de modo efetivo no desenvolvimento de seus filhos com SCZ, por causa dos estímulos nas áreas que a criança apresenta comprometimento tais como: a área motora global e fina, em relação aos sentidos e na cognição, englobando a área da linguagem. Para as mães, é importante utilizar-se das brincadeiras e dos brinquedos para estimulação, conforme pode ser percebido na análise dos vídeos. Como nos afirma Velasco (1996, p. 43) "O brincar nunca deixará de ter o seu papel importante na aprendizagem e na terapia, daí a necessidade de não permitirmos suas transformações negativas e estimularmos a permanência e existência (autêntica e espontânea) da atividade lúdica infantil".

As participantes relataram que preferem oferecer brinquedos coloridos e que emitam algum tipo de som às crianças, por perceber que seus filhos apresentam reações e avanços no seu desenvolvimento. Isso foi possível observar também durante a análise do vídeo, na qual uma das crianças sorri para o mediador familiar que está brincando com ela, demonstrando agitar-se, interagindo com o adulto por intermédio de um brinquedo, um cachorrinho de plástico com guizos que emitiam sons e, por consequência, demonstrando significativos avanços. Ambas mães relataram, ainda, que disponibilizam de duas a três horas diárias para brincar com seus filhos.

Durante as brincadeiras, é perceptível o quanto o brincar envolve o desenvolvimento de emoções, tanto da criança como a cuidadora principal, estreitando assim vínculos afetivos, no qual envolvem a interação familiar, o carinho e o reconhecimento das pessoas consideradas importantes para a criança. Ademais, as crianças, nesses momentos, esboçaram inúmeras reações significativas como: retribuíram sorrisos e buscaram com o direcionamento do olhar, os comandos de voz.

B) O desenvolvimento da criança por meio das brincadeiras

Nessa categoria, uma das perguntas feitas às mães foi: você já teve alguma orientação de profissionais da área da saúde ou da educação sobre as formas de estimular o desenvolvimento do seu 
filho? Ambas responderam que sim. Então, na sequência, elas relataram quais foram essas orientações.

As falas das participantes trazem a preocupação que esses profissionais têm com o processo de desenvolvimento da criança com SCZ. Ressaltaram que nos atendimentos são explicitados a importância da ludicidade, das trocas de informações importantes com a família, relatando, ainda, o quão necessário são os momentos de brincar durante o dia a dia de seus filhos. É durante a atividade do brincar e, principalmente, na manipulação ativa dos brinquedos e participação nas brincadeiras que a criança vem ultrapassando as expectativas dos seus limites, tendo em vista a sua inserção no mundo vasto.

Percebe-se que essas mães passaram a ver a brincadeira como uma importante aliada no processo de desenvolvimento de seus filhos, a partir de que as crianças, mesmo com suas limitações, empolgam-se e demonstram interesses quando são estimuladas com brincadeiras. As mães mencionaram que conseguiram identificar algumas melhoras e avanços consideráveis após incluírem momentos do brincar no cotidiano das crianças. Analisando os vídeos, percebe-se que as gravações das duas crianças brincando confirmam o que as mães relataram nas entrevistas.

Cabe salientar que a motricidade global dessas crianças ainda está em desenvolvimento, pois não conseguem manter o seu controle postural, o que dificulta, às vezes, o movimento corporal. A motricidade global de acordo com Ferland (2009, p. 86) é: "uma atividade na qual a criança aprende a movimentar as diferentes partes de seu corpo de forma harmoniosa". Por ter dificuldade nessa área do seu desenvolvimento, a criança vai precisar trabalhar com alguns instrumentos que a auxilie, o que se atribui a brincadeira e aos brinquedos uma função relevante nesse processo.

\section{C) A visão das progenitoras em relação a aprendizagem das crianças por intermédio das brincadeiras e a futura inclusão escolar.}

Nessa categoria pretende-se discorrer sobre a visão que as participantes percebem do desenvolvimento e aprendizagem de seu filho utilizando as brincadeiras e brinquedos conforme orientação dos especialistas que a criança frequenta. Também destacaremos a percepção das mães acerca da futura inclusão das crianças na escola de Educação infantil.

Perguntamos se as crianças estavam frequentando alguma creche e as respostas das mães foram unânimes que "ainda não", 
e argumentaram: "acredito que precisa mais tempo e adaptação para ele, pois sabemos que não temos creches, escolas, preparadas para recepcionar crianças com esta microcefalia" e "ainda não me sinto confiante".

Nos relatos obtidos, torna-se evidente o quanto as mães evitam matricular as crianças nas creches devido ao que afirmam ser " $a$ falta de preparo dos profissionais" e a não confiança em deixar seus filhos nas escolas. Este argumento também envolveu uma parcela de receio e superproteção, evidenciada ao revelarem o medo que têm de agravos à saúde e uma possível exclusão das crianças no contexto escolar.

Embora, pela perspectiva da educação inclusiva, todas as crianças sejam beneficiadas com as oportunidades da convivência com outras crianças, essas mães demonstraram certa resistência em colocar seus filhos na creche. As justificativas também residiram na insegurança e apreensão quanto as práticas escolares voltadas às crianças com este perfil, realizadas nas creches atualmente. As mães expressaram que as creches não estão preparadas para receber seus filhos devido a outros elementos, tais como estrutura física, quadro de funcionários despreparados, recursos materiais, grande número de crianças em sala de aula, entre outros pontos. Para Mittler (2003) quando pais e profissionais trabalham juntos durante a infância, os resultados são positivos no desenvolvimento e na aprendizagem da criança.

Para ajudar do desenvolvimento de habilidades exigidas pela sociedade deve-se levar em consideração a importância de fazer a matricula das crianças com SCZ em uma creche ou escola de Educação Infantil e de oferecer a orientação e acompanhamento necessário aos pais para que eles possam atuar em parceria com a escola, tendo como objetivo principal o desenvolvimento da criança, além de trabalhar o seu relacionamento social com crianças que apresentam desenvolvimento típico. Como exposto por Lamônica e Ribeiro (2018, p. 184):

A família tem papel fundamental na formação da criança. Os pais, demais familiares e cuidadores devem participar do processo de desenvolvimento para transformar os momentos do cuidado de vida diária em ambientes ricos de estimulação. Além de estimular a criança, podem também observá-la e compreender suas necessidades e dificuldades. 
As autoras complementam que para isso as famílias devem ser orientadas para uma participação colaborativa na realização de atividades estimuladoras no ambiente doméstico, respeitando seus sentimentos, valores sociais e culturais.

No que concerne ao brincar, as progenitoras também consideraram importante a intervenção precoce por meio das brincadeiras para as crianças com SCZ, pois tais brincadeiras e, principalmente, os brinquedos utilizados durante as brincadeiras, auxiliam de maneira evidente o desenvolvimento da criança, aperfeiçoando suas habilidades e detectando também suas dificuldades. Como orienta Ferland (2009) é importante que os pais brinquem com os filhos, vivendo momentos prazerosos em família.

\section{Considerações finais}

O presente estudo visou analisar a importância do brincar para o desenvolvimento das crianças com SCZ, na visão das progenitoras, evidenciando as contribuições relativas ao seu desenvolvimento, já que elas podem se desenvolver e aprender mais durante a brincadeira. Foi possível comprovar o papel fundamental da família, representada nesta pesquisa pelas progenitoras das crianças, enquanto mediadoras nesse tipo de aprendizagem e os benefícios que traz o brincar com seus filhos diariamente, estimulando dessa forma o desenvolvimento integral dessas crianças pequenas.

Compreende-se que as brincadeiras e os brinquedos representam uma linguagem fundamental na infância também para essas crianças, por isso se torna essencial que seja incentivada e compartilhada tanto pela família como pelos professores da Educação Infantil,como forma de trabalhar as capacidades da criança e melhoria de suas habilidades, diante das dificuldades apresentadas.

Os dados revelaram também, o quão as mães estão receosas e apreensivas com a iminente inclusão das suas crianças nas escolas de Educação Infantil. Vimos que os argumentos foram diversos, desde a precariedade de espaços físicos e condições materiais, até a formação dos profissionais de educação que acolherão estas crianças.

Considerando que a escola de Educação Infantil é um contexto potencial de desenvolvimento humano, a creche e a pré-escola, se ainda não o fizeram, terão que se preparar para acolher e trabalhar com bebês e crianças com o diagnóstico de SCZ. Nesse sentido, a adequação de seu espaço físico, a qualidade de materiais 
e, principalmente, a formação dos(as) professores(as) e demais profissionais da instituição, serão fundantes para essa acolhida sensível e prática pedagógica eficaz. Sem embargo, as parcerias com as famílias e profissionais da saúde não são menos importantes, o que demandará diálogos constantes entre ambas instituições.

Conclui-se afirmando o quanto o brincar, como mecanismo essencial na infância, é relevante para aquisições de habilidades psicomotoras, cognitivas, afetivas e sociais no cotidiano das crianças com a SCZ. Tendo em conta a pandemia de casos de crianças nascidas com a SCZ nos últimos anos no país, é urgente elementos que possam contribuir para o atendimento dessas crianças, visando a acolhida e estimulação precoce tanto pelas famílias como pelas escolas. Nesse sentido, é pertinente que as brincadeiras possam ser incluídas em todas as fases do desenvolvimento dessas crianças, em ambientes familiar, social e escolar, adequadas a idade e ao grau de complexidade que apresentam.

\section{El desarrollo del juego en niños con el Síndrome Congénito de Zika Virus}

Resumen: En la perspectiva de la educación inclusiva todos los niños tienen derecho a la educación, independientemente de su condición socioeconómica, cultural o discapacidad. Teniendo en cuenta tal perspectiva, el presente trabajo tuvo como objetivo analizar a través de la visión de las progenitoras, la importancia del jugar para el desarrollo de los niños con el Síndrome Congénito del Zika Virus (SCZ). Se destacan otros objetivos: percibir los aspectos de desarrollo del niño a través de los juegos que realiza, e identificar la opinión de las progenitoras sobre el papel del jugar en el aprendizaje, así como su percepción en la inserción escolar de estos niños. Para responder a los cuestionamientos, se realizó un estudio de campo a través de grabaciones de videos de los niños jugando junto a sus progenitoras, así como también se realizó un cuestionario con ellas. Así, surgieron las siguientes categorías de análisis: 1) el jugar del niño con SCZ; 2) el desarrollo del niño a través del juego y 3) la visión de las progenitoras en relación al aprendizaje de los niños a través de juegos y su futura inserción escolar. De esta forma, se destaca lo importante que es hacer un trabajo lúdico dentro de los contextos de desarrollo, pudiendo ser necesarias algunas correcciones en las metodologías, en los recursos, en los materiales, y en las actividades realizadas para la obtención de respuestas, así como también en las diversas necesidades de aprendizaje del niño con SCZ. Se concluye que el jugar estrecha vínculos y trae beneficios para el proceso de desarrollo, sin embargo la percepción de las progenitoras sobre la escuela inclusiva, reveló en un aspecto, ciertos temores e inseguridades acerca de la inserción de los niños pequeños en las escuelas de Educación Infantil.

Palabras clave: Educación Inclusiva. Síndrome Congénito de Zika Virus. Jugar. Familia. Educación Infantil. 


\title{
The development of playing in children with the Zika Virus Congenital Syndrome
}

\begin{abstract}
From an inclusive educational perspective, all children have the right to education, regardless of their socioeconomic, cultural or disability status. Considering this perspective, the present work aims the analyzes of the importance of play to the development of children with Zika Virus Congenital Syndrome (CZS), in the view of the IR progenitors. The objectives of this study are: to understand aspects of child's development with CZS through the games played and to identify the opinion of the mother about the role of playing in the learning process and their perceptions about the school insertion of these children. To answer the questions, a field study was carried out with the participation of parents of children with the syndrome, in which they answered a questionnaire, besides the observation by the researchers of the children playing during video recordings. Thus, the following categories of analysis emerged: 1) the playing of the child withCZS; 2) the child's development through play; 3 ) the parents' view of children learning through playing and future school insertion. Thus, it is important to note how important it isto do playful work within contexts of development, and it maybe necessary to adapt the methodology, resources, materials and activities carried out to obtain a response to the learning needs of the child with CZS. It is concluded tha tplaying creats boundaries and benefits to development process of these children, however the parents' perception about the inclusive school revealed insecurities and fears regarding the insertion of young children in Early Childhood Education.
\end{abstract}

Keywords: Inclusive Education. Congenital Syndrome of Zica Virus. Playing. Family. Kindergarten.

\section{Referências}

AZEVEDO. A.L. As crianças invisíveis da epidemia de Zica.O Globo, Rio de Janeiro, 30 abr. 2017. Disponível em: https://oglobo.globo.com/ brasil/as-criancas-invisiveis-da-epidemia-de-zika-21275420. Acesso em: 8 de jul. 2018.

BARDIN, L. Análise de conteúdo. Trad. L. de A. Regoe A. Pinheiro. Lisboa: Edições 70, 2011. Obra original publicada em 1977.

BRASIL. [Constituição (1988)]. Constituição da República Federativa do Brasil de 1988. Brasília, DF: Senado, 1988.

BRASIL. Lei no 9.394, de 20 de dezembro de 1996. Estabelece as diretrizes e bases da educação nacional. Diário Oficial da União: Brasília, DF, 23 dez.1996.

BRASIL. Ministério da Educação. Política Nacional de Educação Especial na Perspectiva da Educação Inclusiva. Brasília, DF, 2008. Documento elaborado pelo Grupo de Trabalho nomeado pela Portaria $n^{0} 555 / 2007$, prorrogada pela Portaria $n^{\circ} 948 / 2007$, entregue ao Ministro da Educação em 07 de janeiro de 2008. 
BRASIL. Ministério da Educação. Secretaria de Educação

BásicaDiretrizes Curriculares Nacionais para a Educação Infantil. Brasília, DF, 2010.

BRASIL. Ministério da Saúde. Secretaria de Atenção à Saúde. Diretrizes de estimulação precoce: crianças de zero a 3 anos com atraso no desenvolvimento neuropsicomotor decorrente de microcefalia.Brasília, DF, 2016a.

BRASIL. Ministério da Saúde. Brasil adota recomendação da OMS e reduz medida para microcefatia. Brasília, DF, 2016b. Disponível em:http://portalms. saude.gov.br/noticias/agencia-saude/22553-brasil-adota-recomendacao-daoms-e-reduz-medida-para-microcefalia. Acesso em: 25 maio 2019

BRASIL. Ministério da Saúde. Secretaria de Atenção à Saúde. Protocolo de atenção à saúde e resposta à ocorrência de microcefalia relacionada à infecção pelo vírus Zika. Brasília: Ministério da Saúde, 2016c, 42 p. Disponível em: < http://portalarquivos.saude.gov.br/images/pdf/ protocolo-sas-2.pdf > Acesso em: 24 out. 2017.

BRASIL. Ministério da Saúde.Portaria $n^{\circ}$ 3.502, de 19 de dezembro de 2017.Institui, no âmbito do Sistema Único de Saúde a Estratégia de fortalecimento das ações de cuidado das crianças suspeitas ou confirmadas para Síndrome Congênita associada à infecção pelo vírus Zika e outras síndromes causadas por sífilis, toxoplasmose, rubéola, citomegalovírus e herpes vírus.Diário Oficial da União: seção 1, Brasília, DF, n. 245,p. 124-155, 22 dez. 2017.Disponível em:http://bvsms.saude. gov.br/bvs/saudelegis/gm/2017/prt3502_22_12_2017.html. Acesso em: 16 jun. 2019.

BRASIL. Lei $\mathrm{n}^{0}$ 13.146, de 6 de julho de 2015. Institui a Lei Brasileira de Inclusão da Pessoa com Deficiência. Diário Oficial da União: Brasília, DF, 7 jul. 2015. Disponível em: http://www.planalto.gov.br/ccivil_03/_ ato2015-2018/2015/lei/113146.htm. Acesso em: 11 out. 2017.

BRASIL. Ministério da Saúde. Secretaria de Atenção à Saúde. Protocolo de atenção à saúde e resposta à ocorrência de microcefalia relacionada à infecção pelo vírus Zika. Brasília, DF, 2016. Disponível em: < http:// portalarquivos.saude.gov.br/images/pdf/protocolo-sas-2.pdf > Acesso em: 24 out. 2017.

BRASIL. Ministério da Educação. Base Nacional Comum Curricular: educação é a base. Brasília, DF, 2017.Disponível em: http:// basenacionalcomum.mec.gov.br/images/BNCC_EI_EF_110518_ versaofinal_site.pdf. Acesso em: 8 jul. 2018.

COLL, C.; PALACIOS, J.; MARCHESI, A. Desenvolvimento psicológico e educação: necessidades educativas especiais e aprendizagem escolar. 2. ed. Porto Alegre: Editora Artes Médicas, 1995.

FERLAND, F. Além da deficiência fisica ou intelectual: um filho a ser descoberto. Londrina: Lazer \& Sport,2009. 
FONSECA, V. Aprender a aprender: a educabilidade cognitiva. Porto Alegre: ARTMED, 1998.

FREITAS, B.P. et al. Ocular Findings in infants with microcephaly associated with presumed Zika Virus Congenital Infection in Salvador, Brasil. JAMA Ophthalmol, Chicago, v. 134, n. 5, p. 529-535, 2016.

FRIEDMANN, A. O direito de brincar: a brinquedoteca. São Paulo: Scritta: ABRINQ. 1992.

HAEtinger, M. G. O universo criativo da criança na educação. Porto Alegre: Instituto Criar, 2005. (Coleção Criar, 3).

KISHIMOTO, T.M. Brinquedos e brincadeiras na educação infantil. In; SEMINÁRIO NACIONAL: CURRÍCULO EM MOVIMENTO PERSPECTIVAS ATUAIS. 1., 2010, Belo Horizonte. Anais [...] Belo Horizonte: [s. n.], 2010. Disponível em: < http://portal.mec.gov.br/ index.php?option $=$ com_docmanEview $=$ downloadEalias $=7155-2-3$ brinquedos-brincadeiras-tizuko-morchida\&category_slug = dezembro2010-pdfEItemid=30192 >. Acesso em 28 jun. 2019.

LAMÔNICA, D. A. C.; RIBEIRO, C. C. Zika vírus, Microcefatia e estimulação precoce: a urgência do debate. In: OLIVEIRA, A. A. S.; PAIXÃO, K. M. G.; PAPIM, A. A. P. (org.) Educação Especial e inclusiva: contornos contemporâneos em educação e saúde. Curitiba: Editora CRV, 2018. p. 177-190.

MENDES, E. G. A radicalização do debate sobre inclusão escolar no Brasil. Revista Brasileira de Educação, Campinas, v. 11, n. 33, set./dez. 2006, p. 387-405.

MITTLER, P. Educação inclusiva: contextos sociais. Porto Alegre: Artmed, 2003.

ORGANIZAÇÃO MUNDIAL DE SAÚDE. CIF: Classificação internacional de funcionalidade, incapacidade e saúde. Lisboa, 2004.

PEREIRA, S. O; LIMBERGER, J. A. O sentido do brincar como ato educativo. Revista Eletronica Interdisciplinar, Barra da Graça, v. 1, n. 11. v. 1. p. 71-76, 2014.

UNESCO. Procedimentos-Padrões das Nações Unidas para a Equalização de Oportunidades para Pessoas Portadoras de Deficiências, A/RES/48/96, Resolução das Nações Unidas adotada em Assembleia Geral. Conferência Mundial sobre Necessidades Educacionais Especiais de Salamanca,1994. Disponível em: http://portal.mec.gov.br/seesp/ arquivos/pdf/salamanca.pdf. Acesso em: 28 jun. 2019.

UNESCO. Convenção sobre os Direitos das Pessoas com Deficiência, Nova Iorque, 30 de março de 2007.

SIAULYS, M. O. C. Brincar para todos. Brasília, DF: Ministério da Educação, Secretaria de Educação Especial,2005.

STAINBACK, S.; STAINBACK W. Inclusão: um guia para educadores. Porto Alegre: Artmed Editora, 1999. 
TORRES, V. F.; TAPIA, L. S. Escola Inclusiva: o aluno com microcefalia, o que a escola pode fazer? 2017. Disponível em: http://www.

crechesegura.com.br/escola-inclusiva-o-aluno-com-microcefalia/.

Acesso em 24maio 2019.

VAN EYKEN, E. B. B. D; SÁ M.R.C. Avaliação neurofuncional da criança com sindrome congênita associada ao vírus Zika. In: GARCIA C.S.N.B.;

FACCHINETTI, L. D. (org.) Associação Brasileira de Fisioterapia

Neurofuncional; PROFISIO Programa de atualização em fisioterapia:

Ciclo 5. Porto Alegre: Artmed Panamericana; 2017. p. 87-119. (Sistema

de Educação Continuada a Distância,1). Disponível em: http://

www.portalsecad.com.br/demoArtigo.php?programa =38Eutm_

source $=$ facebookEutm_medium = cpcÉtm_campaign = at_leads\&utm_

content $=$ fisioterapia_profisio_neuroE utm_term = captacao_de_leads.

Acesso em: 24 mar. 2018.

VELASCO, C. G. Brincar, o despertar psicomotor. Rio de Janeiro: Sprint Editora, 1996.

Submetido: 10 de agosto de 2018

Aceito: 3 de junho de 2019 
